\title{
When Written Corrective Feedback Is Ineffective in Second-Language Grammar Acquisition
}

\author{
Douglas J. Wulf \\ Department of English, George Mason University, Fairfax, Virginia, USA \\ Email: dwulf@gmu.edu
}

How to cite this paper: Wulf, D. J. (2021). When Written Corrective Feedback Is Ineffective in Second-Language Grammar Acquisition. Open Journal of Modern Linguistics, 11, 577-592.

https://doi.org/10.4236/ojml.2021.114044

Received: July 1, 2021

Accepted: July 27, 2021

Published: July 30, 2021

Copyright $\odot 2021$ by author(s) and Scientific Research Publishing Inc. This work is licensed under the Creative Commons Attribution International License (CC BY 4.0).

http://creativecommons.org/licenses/by/4.0/

\begin{abstract}
This paper describes an opportunity for theoretical linguists to make a particular sort of contribution to the teaching of second-language (L2) grammar. Currently, a popular procedure in L2 instruction for teaching grammar is indirect Written Corrective Feedback (WCF). In this procedure, instructors do not provide corrections but rather merely flag L2 students' errors with proofreading symbols. These symbols are intended to guide learners to self-correct errors, and it is hoped that through this process, learners might make fewer errors in future writing with these points of grammar. Despite its widespread use, there is evidence that indirect WCF only leads to increased competence for a limited subset of grammatical patterns, exerting no significant positive effect with points of grammar not in this subset. A plausible explanation in such cases is that indirect WCF can fail to provide learners with sufficient feedback to acquire the grammatical paradigm. In such cases, direct WCF may be more helpful, but there is another option, which is to supplement indirect or direct WCF with metalinguistic explanation (ME) of targeted grammatical structures. However, the exact nature of this ME could be critical. As the view of language acquisition depicted under Skill Acquisition Theory (SAT) would predict, learners would specifically require ME that consists of accurate and concisely formulated declarative knowledge of the grammar point in a format that permits the pattern to be proceduralized and eventually automatized. Since formulating concise, accurate, and proceduralizable declarative knowledge for grammar points is a challenge in and of itself, theoretical linguists could pursue this objective and thus helpfully make a particular contribution to L2 grammar instruction. Addressing learner errors involving the articles in English is discussed as an example.
\end{abstract}

\section{Keywords}

Theoretical Linguistics, Applied Linguistics, Grammar, Second Language 
Acquisition, Skill Acquisition Theory, Written Corrective Feedback, Error Correction, Accuracy Improvement, Treating Linguistics Errors, Second Language Writing, Language Learning, English Article System

\section{Introduction}

Written Corrective Feedback (WCF) is today a common procedure for teaching writing, to include second-language (L2) writing instruction. Russell and Spada (2006: p. 134) define Corrective Feedback (CF) as "any feedback provided to a learner, from any source, that contains evidence of learner error of language form. It may be oral or written, implicit or explicit." WCF is simply CF provided to a learner in written form. Among the many aspects of writing taught via this procedure, WCF is thought to help L2 learners to acquire grammar.

Considering WCF broadly, we find a dichotomy between the direct and indirect options for WCF. In direct WCF, the instructor notes grammatical errors in student writing and provides the correct form explicitly. Indirect WCF, however, involves merely flagging writing errors with proofreading marks (e.g., $s-v$ for a subject-verb agreement error, $v t$ for a verb tense error, etc.), but not providing the correction. Rather, students are challenged to self-correct flagged errors themselves. The hope is that revision guided through WCF, very often in the form of indirect WCF, will gradually lead to fewer errors in future writing, indicating that this feedback has helped learners to achieve improved accuracy and grammatical competence.

Yet, there has been controversy over the effectiveness of indirect WCF (and WCF more generally) as a pedagogical practice. On the one hand, Ferris (1999) claimed that there exists "mounting research evidence that effective error correction-that is selective, prioritized, and clear-can and does help at least some student writers" (p. 4). On the other hand, Truscott (1996: p. 328) argued, "Grammar correction has no place in writing courses and should be abandoned," claiming that "research evidence shows that grammar correction is ineffective."

An important practical concern is certainly involved here. Providing WCF involves time and effort expended both for teachers and for students. If WCF is of only minimal assistance, is of no assistance, or is even somewhat harmful for learners, it would not be worth the expenditure of time and effort. On the other hand, the issue may come down to the quality of WCF provided. That is, quality WCF (which remains to be defined for the moment) may indeed be beneficial and thus worth the time and effort involved, whereas WCF that is lacking in quality would be a waste of time and effort. Given this, it is important to try to pin down how exactly quality WCF might be formulated.

Wide differences of opinion about WCF may in part be due to the way research on WCF has often been conducted. Wagner and Wulf (2016) note that WCF studies have often been either too broad or too narrow in their scope. Broadly focused studies (Lalande, 1982; Robb, Ross, \& Shortreed, 1986; Fathman \& Whal- 
ley, 1990; Kepner, 1991; Truscott, 1996, 1999, 2004, 2007; Polio, Fleck, \& Leder, 1998; Ferris, 1999, 2004, 2010; Ashwell, 2000; Ferris \& Roberts, 2001; Truscott \& $\mathrm{Hsu}, 2008$ ) have only examined whether WCF works overall without noting potential contrasts in WCF's impact with specific grammatical constructions. Narrowly focused studies (Sheen, 2007; Bitchener, 2008; Bitchener \& Knoch, 2008; Ellis, Sheen, Murakami, \& Takashima, 2008; Bitchener \& Knoch, 2009, 2010; Sheen, 2010; Shintani \& Ellis, 2013) have examined WCF with only a single grammatical construction or even just part of a grammatical paradigm, but the results of such studies cannot provide us with a clear picture of how and why indirect WCF suffices or fails to suffice for helping students acquire various L2 grammatical paradigms.

Seeking to provide a clearer, more detailed picture of the effectiveness of indirect WCF, Wagner and Wulf (2016) conducted a study which tracked individual error types in the writing of students receiving indirect WCF versus those not receiving indirect $\mathrm{WCF}$. Their results indicate that some individual error types are amenable to significant change via indirect WCF, whereas others are not. The question then arises what to do for those points of grammar for which instruction via indirect WCF is of no help. This paper offers a suggestion of what might be done when indirect WCF is ineffective in L2 grammar acquisition. To formulate improved feedback to learners, it will first be necessary to categorize what sort of errors seem not to be amenable to treatment via indirect WCF and also to advance a plausible reason why indirect WCF might not be successful for these error types.

Stubborn errors in grammar may be more amenable to direct WCF or, especially, to WCF (direct or indirect) supplemented with metalinguistic explanation (ME), as discussed below. However, as will also be noted, the quality and quantity of this $\mathrm{ME}$ will plausibly be of central relevance to the success or failure of any WCF + ME feedback procedure. In particular, this paper argues that ME provided in the context of feedback on grammar could be particularly helpful if the $\mathrm{ME}$ is formulated in conformity with the view of language acquisition described under Skill Acquisition Theory (SAT). This is because the ME would not simply be informative to learners, but would also be designed to be of immediate practical utility to the learners in the process of grammar acquisition, assuming we regard this process as the acquisition of a skill or a set of skills.

Thus, the basic rationale for writing this paper is to highlight the importance of providing feedback and grammatical explanations to learners that we may anticipate can successfully be used by the learners to assist in the acquisition of targeted grammatical patterns. In this regard, the feedback provided must be accurate, sufficiently informative, and formatted so that it can be easily proceduralized (i.e., implemented in actual language practice). The formulation of such feedback represents a challenge for theoretical linguists to address (or theoretical linguists working in collaboration with applied linguists and experts in language pedagogy). The example of providing WCF $+\mathrm{ME}$ to address learner 
errors involving the articles in English is discussed in some detail below.

\section{Binary and Non-Binary Rule-Based Grammatical Paradigms}

Ferris (1999) acknowledged that WCF may not have uniform effectiveness across all error types or grammatical categories, introducing the notion of treatable errors versus non-treatable errors. Ferris argued that treatable errors would be those that are rule based (i.e., there are rules that can be taught, learned, or looked up in a grammar book), whereas non-treatable errors would be idiosyncratic (i.e., there are no systematic rules to learn). However, adopting Ferris' terminology, Wagner and Wulf (2016) found that errors treatable via indirect WCF were even more narrowly defined than simply errors involving rule-based points of grammar.

It should be emphasized that so-called "non-treatable" error types would not necessarily be entirely impervious to improvement over time. Learners may indeed exhibit error reduction of such non-treatable errors as their L2 acquisition proceeds. However, the key point is that research may potentially reveal no statistically significant difference in error rates over time for certain error types between two groups of students receiving WCF versus those not receiving WCF, assuming the instruction of these two groups of students is otherwise comparable. That is, errors would be considered non-treatable via WCF if there is no significantly measurable difference in students statistically between students provided with WCF and those not provided with WCF.

In this regard, Wagner and Wulf (2016) found that only rule-based errors exhibiting a binary paradigm were amenable to positive change via indirect WCF, but not rule-based errors with a non-binary paradigm. For example, subject-verb agreement in English is a binary paradigm because there are only two options involved (i.e., singular versus plural). However, verb tense in English can be regarded as a non-binary paradigm because there are more than just two tenseaspect options in English (e.g., simple present tense, present progressive, past perfect, past perfect progressive, etc.). Subject-verb agreement errors (a binary paradigm) were found to be treatable via WCF, whereas verb tense errors (a nonbinary paradigm) were found to be non-treatable via WCF.

The study from Wagner and Wulf (2016) can be summarized briefly. The study consisted of 33 participants $(n=33)$ who were L2 English ninth and tenth grade high school students in Northern Virginia taking an English language learner writing course at either the intermediate or advanced English proficiency level. The participants were from a variety of countries and language backgrounds with ages ranging from 14 to 18 . At both intermediate and advanced levels, participants were randomly placed either into an experimental group (receiving WCF during the revising/editing step for their writing assignments) or a control group (receiving no WCF and simply being asked to "look for errors and try to correct them" in the revising/editing step). Thus, the study had experimental versus con- 
trol groups at the intermediate level and experimental versus control groups at the advanced level.

Of the eleven targeted error categories tracked, four were grammatical errors. These were flagged for study participants using specific correction symbols: 1) subject-verb agreement (symbol: s-v), such as He love his wife, 2) verb tense (symbol: $v t$ ), such as $I$ will be in class yesterday, 3) singular-plural agreement (symbol: num), such as I have many dog at home, and 4) article usage (symbol: art/no art), such as $M y$ friend is a best one in city. Participants completed four 200 -word paragraphs over a 12-week elicitation period. For the experimental group but not for the control group, correction symbols were added to the writing samples between classes. Otherwise, for each of the two proficiency levels studied, an effort was made to keep the instruction of an experimental group and its corresponding control group comparable.

The measure of the impact of indirect WCF broadly for all error types (linguistic/grammatical, word usage, and mechanical) demonstrated a statistically significant difference in the reduction of errors over the four elicitation tasks between participants from both proficiency groups. That is, the experimental groups reduced errors significantly better in each subsequent writing assignment than control groups over the elicitation period. Likewise, considering grammatical errors overall, both experimental groups reduced grammatical errors as a category significantly better across the four elicitation tasks relative to both control groups. Thus, looking only at the overall picture, as has often been the case under the many broadly focused studies listed above, indirect WCF gave the impression of being entirely successful.

However, when individual error categories were examined more closely, it was crucially found that indirect WCF did not have a uniformly positive impact for all four grammatical error categories. In particular, both singular/plural errors (at least at the intermediate proficiency level) and subject-verb agreement errors (at both the intermediate and advanced levels) were shown to be amenable to improvement via indirect WCF. By contrast, no statistically significant differences were found between the experimental and control groups at either proficiency level with respect to verb tense errors or article errors, consistent with the notion that indirect WCF had been ineffective for assisting the learners to build improved grammatical proficiency with these error types. This briefly summarizes the results of the study. Further details can be found by consulting Wagner and Wulf (2016).

It is reasonable to suppose that this contrast in treatability has something to do with the inherent complexity of the grammatical paradigms involved. In this regard, Wagner and Wulf (2016) noted that both the singular/plural and subject-verb agreement paradigms are binary in that they are paradigms involving only two options. That is, singular/plural errors involve either incorrectly using a singular form instead of a plural form or incorrectly using a plural form instead of a singular form. Most plurals in English simply involve a choice of using the 
$-s$ suffix or not, with only a small set of nouns taking an irregular plural form (e.g., goose/geese). Likewise, subject-verb agreement errors involve a binary contrast only, so that when a subject-verb agreement error is flagged, there is only one remaining option to use for the correction.

On the other hand, the article paradigm in English involves a non-binary contrast. A language user must decide whether to select the definite article the, either of two forms of the indefinite article a/ an, no article whatsoever, or an indefinite expression of quantity (e.g., some, a lot off). Similarly, there are a variety of verb tense (tense-aspect) options, such as simple past, present progressive, past perfect progressive, and so forth. Thus, there is not a single remaining option when correcting a verb tense error, for example, but many options remaining from which to select.

In addition, Wagner (2016) found that an error involving an idiosyncratic binary paradigm was also non-treatable via indirect WCF. Thus, there is evidence that the set of treatable errors via indirect WCF is limited to those involving binary rule-based paradigms only. Rule-based errors involving non-binary rulebased paradigms and even the simplest paradigm for idiosyncratic errors (idiosyncratic errors involving merely a binary contrast) seem non-treatable via indirect WCF.

\section{Providing Sufficient Feedback to Assist with Acquisition}

Wagner and Wulf (2016) argue that the reason indirect WCF is effective in helping acquisition of binary rule-based grammatical paradigms but ineffective for the acquisition of non-binary rule-based grammatical paradigms is that indirect WCF is guaranteed to provide sufficient feedback for acquiring a binary paradigm, but provides insufficient feedback for acquiring a non-binary paradigm. Consider that flagging errors in a binary paradigm is akin to flagging errors in a true/false test. If a student is tasked with revising mistakes made in a true/false test, and the teacher has indicated that an answer of "true" was incorrect for a particular question, it will be easy enough for the student to come up with the correct answer on a second attempt. Indeed, flagging errors in binary paradigms is tantamount to providing the correction directly. Over time, through a process of inductive learning, it is plausible that learners could also begin to come to an understanding of why the paradigm is split into these two categories.

By contrast, using indirect WCF to address errors with non-binary grammatical paradigms can be seen as analogous to flagging errors on a multiple-choice test. If a student is tasked with revising mistakes made in a multiple-choice test, and the teacher has indicated that answer " $D$ " was incorrect for a particular question, the student must still select from answers "A," "B," or "C" in the revision process. For non-binary paradigms, indirect WCF tells the learner only that one option is incorrect, but not what the correct option is. Since revision following indirect WCF does not ensure that the student will come up with the correct form even on the second attempt, it will plausibly be more difficult also 
for learners to come to an overall understanding of this non-binary paradigm through inductive learning. Indeed, such limitations of indirect WCF have been noted in the past. For example, Chandler (2003) has argued that indirect WCF simply provides insufficient information to resolve complex errors.

Wagner and Wulf (2016) thus argue that indirect WCF is an ineffective procedure for helping L2 learners acquire non-binary rule-based grammatical paradigms because, in such cases, indirect WCF simply does not provide learners with enough feedback. In fact, the requirement for learners receiving indirect WCF to acquire patterns implicitly and inductively can plausibly be burdensome, especially for lower proficiency learners. This was indeed found in a qualitative study conducted by Fhaeizdhyall (2020). The main reason students gave in situations where indirect WCF prevented them from improving their accuracy in targeted linguistic structures was "lack of information about the errors."

Wagner and Wulf (2016) indicate that direct WCF (i.e., providing the correct revision) could possibly prove more effective for helping learners acquire nonbinary paradigms. They note that Bitchener and Knoch (2010) list among the strengths of direct feedback "reducing confusion" and "resolving complex errors" (pp. 209-210). Others have also championed direct WCF for similar reasons (e.g., Sheen, 2007; Bitchener, 2008; Ellis, Sheen, Murakami \& Takashima, 2008).

Yet, even though the feedback provided via direct WCF is explicit rather than implicit, directly providing learners with corrections still challenges learners to synthesize the rule or rules of non-binary rule-based paradigms through inductive reasoning. That is, learners must still gradually come to an understanding of the potentially complex rules of non-binary grammatical paradigms through encountering incorrect and correct examples of their use. While this seems possible, acquisition could be slow and frustrating, especially in cases of paradigms with many different forms, such as the system of verb tenses in English. Indeed, Nassaji (2011) found that oral negotiated feedback (i.e., conversing with students about errors in writing) was more effective than non-negotiated direct WCF for treating article errors due to the complexity of the article paradigm in English. It thus seems that even direct WCF can be more valuable to learners if augmented in some fashion, such as Nassaji (2011) has shown with the utility of supplementing direct WCF with oral negotiation about errors and rules.

The implication is that WCF, both indirect and direct, can to some extent be lacking in providing the level of information that learners require to make progress in the acquisition of grammatical paradigms beyond those of minimal complexity (i.e., binary rule-based paradigms). Thus, another pedagogical possibility to consider is to augment indirect or direct WCF with metalinguistic explanation (ME), which is to provide learners with some sort of explicit description of the paradigm and/or grammatical rules under consideration. The strategy of WCF + ME seems maximally informative in that the learner does not need to arrive at the rules or a description of the paradigm through inductive reasoning but is rather explicitly provided with this information. 


\section{Metalinguistic Explanation and Skill Acquisition Theory}

Recent WCF studies have indeed examined results of the option of WCF + ME. However, Fhaeizdhyall (2020) notes with regard to this procedure, "Clearly, the role of metalinguistic information has garnered mixed findings" (p. 153). For example, the studies of Sheen (2007) and Shintani, Ellis and Suzuki (2013) found ME to have a positive effect, whereas the studies of Stefanou \& Révész (2015) and Gorman \& Ellis (2019) found ME to be of no additional benefit to learners when compared with learners receiving WCF alone. Thus, at present, the best that we can perhaps conclude from the previous literature is that metalinguistic information seems at least to have the potential in some cases to assist learners to acquire grammatical structures, thereby encouraging us to continue to investigate this option.

Without attempting to delve into a detailed analysis of previous studies concerning the value of supplementing WCF with ME, it should be noted that the success or failure of this sort of procedure would certainly depend on the quality and quantity of the metalinguistic information provided to students. To begin with, it almost goes without saying that the information provided would obviously need to be accurate. Learners could not be expected to be aided in their acquisition of a grammatical paradigm by receiving inaccurate metalinguistic information.

However, whether ME would be a benefit, a hindrance, or of no value to learners would not merely be a matter of the contrast between accurate and inaccurate information. The potential value of ME can be understood if we consider the view of language depicted under Skill Acquisition Theory (SAT) (Anderson, 1976; McLaughlin, 1987; DeKeyser, 1998, 2001, 2007). Language acquisition under SAT is just treated as a specific instance of the more general phenomenon of skill acquisition. In this view, ME would only have value if it is formulated in such a way that the learner can actually make use of it.

According to SAT, the acquisition of any skill, such as learning to play a musical instrument, begins with imparting knowledge about the skill to the learner (e.g., "To play a B flat, cover these holes."). This sort of information is termed declarative knowledge. This knowledge must be provided in a format that permits the learner to proceduralize it. That is, through practice, the learner can implement the declarative knowledge in actual performance, thereby developing procedural knowledge (e.g., being able to play a B flat on the instrument successfully when required to do so). With more practice, procedural implementation of the skill becomes easier. Eventually, procedural knowledge can become internalized and can be implemented unconsciously (e.g., playing a B flat note in a song because the tune requires it, but without the player needing to consciously reflect on how to play a B flat). This is called automatization. As with acquiring the skill of playing music, we can regard acquiring the skill of using the grammar of a language as proceeding through the steps of acquiring declarative knowledge, converting this into procedural knowledge, and, finally, automatiza- 
tion.

We can think of the procedure of revision of grammatical errors via WCF as providing L2 learners with certain declarative knowledge. For example, under the SAT view of language acquisition, we may conclude that for binary grammatical paradigms, indirect WCF seems to provide learners with sufficient declarative knowledge in a form that allows for its gradual proceduralization (i.e., converting the declarative knowledge to procedural knowledge) and automatization (i.e., implementing the procedural knowledge with little or no conscious focus). However, in the case of non-binary grammatical paradigms, we may conclude that indirect WCF fails to provide learners with sufficient declarative knowledge in a format that fosters the successful proceduralization and automatization of the paradigm.

If the description of L2 acquisition suggested under SAT is valid, then the task of how language teachers can effectively assist L2 learners to acquire complex (i.e., non-binary) rule-based grammatical paradigms effectively is clearly delineated. In such cases, what L2 learners need is accurate and clearly stated declarative knowledge of the rule-based grammatical paradigm that is formulated in a way to allow for maximally easy proceduralization, and then eventual automatization of the paradigm.

\section{An Example of Proceduralizable ME: The Article System in English}

One of the most investigated types of errors examined in WCF studies are those involving the English article system (e.g., Bitchener, Young, \& Cameron, 2005; Sheen, 2007; Bitchener, 2008; Bitchener \& Knoch, 2008, 2009, 2010; Ellis, Sheen, Murakami, \& Takashima, 2008; Sheen, 2010; Shintani \& Ellis, 2013; Stefanou \& Révész, 2015). As noted above, both indirect and direct WCF, though differing in their level of explicitness, are designed to assist learners to acquire points of grammar and other language features through inductive reasoning. That is, it is hoped that learners can come to an understanding of how the language works by comparing counterexamples (i.e., errors) with grammatical examples of usage (i.e., corrections).

Yet, we might well anticipate that learners will be unable to acquire accurate use of the articles inductively through WCF. The definite article the is the most common word in the English language, and if we combine instances of $a$ and an, the indefinite article is the fourth most common (Sinclair, 1991). Master (1997) notes that the null article, which can be regarded as having no overt article with non-count and plural nouns (e.g., we need $\varnothing$ advice; $\varnothing$ rules are necessary) is an even more frequent pattern than the definite article pattern. Thus, from their first exposure to the English language, L2 learners encounter myriad examples of the grammatical use of articles.

As Leroux and Kendall (2018) note, "While variation between the, a, and absent articles occurs with high frequency in both spoken and written English, the nature and purpose of this variation can be opaque to learners (as well as native 
speakers)" (p. 13). Given this, we should expect that learners will not measurably be helped by yet more examples and counterexamples of article use. It is plausible that learners will require more information about articles than either indirect or direct WCF provides. That is, learners apparently require some form of ME.

Taking SAT into account, we can consider what sort of ME would be predicted to be helpful toward the acquisition of the article system. Under SAT, ME fills the role of imparting declarative knowledge, but crucially the learner must then be able to convert this declarative knowledge into procedural knowledge. Thus, the learner crucially requires accurate and proceduralizable ME. That is, they need declarative knowledge about articles in English that can be easily converted into procedural knowledge.

Part of the difficulty of formulating ME for the article paradigm in English is that, considering articles from a theoretical point of view, the words we label as articles do not, in fact, genuinely form a single paradigm. This can be demonstrated by examining the widely contrasting etymology of the articles in English, as described in Wulf (2016). The indefinite article, a/an, is historically derived from the number one. As it so happens, the indefinite article in modern English indeed still retains a function similar to an expression of quantity. For example, the indefinite article expresses indefiniteness in the same way and for the same reason as all counting numbers express indefiniteness. To illustrate, suppose there are an assortment of pencils on a table. If a person is told "Take three pencils," it would be fine for the person to take any three. Likewise, if a person is told "Take a pencil," it would be fine for the person to take any one of them. Indeed, even though the indefinite article and the number one are distinct words in modern English, Dryer (2013) indicates, "Many languages use the numeral for 'one' in contexts where English would use the indefinite article."

By contrast, the definite article, the, does not function as a quantity expression. Rather, etymologically, the and the demonstrative that were once two forms of the same word. At a time in history when English still retained grammatical gender on nouns, the was the masculine demonstrative and that was the neuter demonstrative. The definite article in modern English still retains a pointing function, similar to the demonstrative expressions this, that, these, and those. Linguists have long recognized this association. For example, the traditional grammarian Henry Sweet grouped the grammatically with demonstratives (Sweet, 1900), and Otto Jespersen treated the as a "weakened" form of that (Jespersen, 1933). To illustrate, suppose there are an assortment of pencils on a table. If a person is told "Take that green pencil," the speaker is saying to take a particular pencil (that green one). This is quite similar to saying "Take the green pencil." Again, the instructions are to take a particular pencil (the green one). The definite article can be used to form a definite description, which is a description that contains enough information such that its intended reference can reliably be identified. That is, a definite description "points out" its reference, so to speak.

The indefinite article, regarded as a singular indefinite quantity expression, 
rather than forming a paradigm with the definite article, could be more usefully regarded as belonging to a paradigm (a singular versus plural/non-count paradigm) with plural/non-count quantity expressions, such as some and a lot of. There are also quantity expressions used only with plural nouns, but not noncount nouns, such as several and the counting numbers (e.g., three, twenty-seven). Again, assuming there are various pencils on a table, if a person is told "Take some pencils," the person could take various pencils, though it would not matter which ones.

One complication of plural/non-count indefinite quantity expressionsis that they can optionally be omitted, resulting in the so-called "null" article: "Take some pencils"/ Take Ø pencils" or "Take some sugar"/"Take Ø sugar." Even today, the null article option is often overlooked so that learners are told that the articles in English consist of a, an, and the. This persists even though the null article has long been recognized by linguists and grammarians. For example, in 1939, the grammarian Paul Christophersen included the null article alongside the indefinite article and the definite article as one of the three article options in English (Christophersen, 1939).

Ignoring the null article pattern in providing feedback to learners is particularly unfortunate, as the existence of this null pattern goes a long way to clarifying many points of confusion regarding article use. For example, the common error of dropping the definite or indefinite article can be clarified if learners realize that English grammar uses the omission of an article in meaningful ways. Lack of an article can indicate either the plural or non-count indefinite meaning with a common noun (e.g., "Take pencils"/"Take sugar"), to indicate that the noun is not a common noun but rather a proper noun (e.g., "He lives in Chicago."), and in certain prepositional phrases (e.g., "He is at college" versus " $\mathrm{He}$ is at a college.").

The definite article the would be more accurately understood to be in a paradigm with other expressions that indicate definiteness. These include demonstratives (i.e., this, that, these, and those) and possessives (e.g., my, your, that lady's, etc.). Incidentally, proper nouns (e.g., Mary, Chicago, etc.) are also inherently definite (so therefore take no article, definite or indefinite). Of course, if a proper noun is reanalyzed as a common noun, then it can take an article, a demonstrative, or related expressions (e.g., I sat next to this Mary, not that Mary).

However, learners would not necessarily need to be taught all these details. Rather, this sort of analysis could simply be used to formulate accurate declarative knowledge of the various grammatical elements that learners can immediately proceduralize. For example, Wulf (2016) suggests the diagnostics given in (1) for testing when to use each article option in English:

$$
\begin{array}{lll}
\text { a/an the indefinite article } & \text { Try "one" } \\
\varnothing & \text { the null article } & \text { Try "some" or "a lot of" } \\
\text { the } & \text { the definite article } & \text { Try "that" or "those" }
\end{array}
$$

Additional note: The definite article "the" introduces a definite description 
To illustrate this set of diagnostics, Wulf (2016) gives the example $\mathrm{He}$ found fish. If an English language learner is taught that the articles (a/an, $\varnothing$, and the) in English form a single functional paradigm, this implies that there ought to be a particular "correct" answer to fill in a blank and a sentence such as this. However, note that all the variant clauses He found a fish, He found fish, and $H e$ found the fish are all grammatical, though these clauses obviously differ in meaning. This is possible because indefinite and definite expressions in English, while used in contrasting ways, belong to separate grammatical paradigms in English, not from one and the same paradigm.

However, the learner need not be concerned with this. Rather, the learner only needs guidance of how and when each of these article options can be used in context. For this purpose, the diagnostics in (1) can be implemented. As the diagnostics indicate, He found a fish is similar in meaning to He found one fish. By contrast, He found fish is similar in meaning to He found some fish or $\mathrm{He}$ found a lot of fish. Finally, He found the fish is similar in meaning to He found that fish or He found those fish.

An objection might be raised that the meaning correspondences in the diagnostics are not exact. For example, He found fish admittedly does not mean exactly the same as He found a lot of fish. Yet, the point of these diagnostics is not that the meanings correspond precisely. Rather, these three diagnostics are helpful because the learner can consider which of the three options provides the best semantic fit in the given context of use. The meaning correspondence in question simply needs to fit more closely than the other two to allow the learner to proceduralize article use in English.

In a study conducted by Wulf (2016), a high-intermediate group of learners was able to correct $46 \%$ of the article errors in their own writing by using these article diagnostics in comparison to successfully correcting only $3.8 \%$ of their article errors before being given these diagnostics. This demonstrates that declarative knowledge (or metalinguistic explanation) provided via these diagnostics can successfully assist with accurate proceduralization in locating and self-correcting article errors even when these have not been flagged by any form of WCF. The point here is not to claim that the diagnostics provided in (1) would be the only diagnostics or the most ideal diagnostics that might be provided to learners. Rather, the claim is simply that (1) represents declarative knowledge of the articles in English that seems sufficiently accurate and sufficiently proceduralizable to be of practical utility to English language learners attempting to acquire use of the articles in English.

\section{Conclusion}

It seems clear that WCF, indirect or direct, is simply ineffective for treating some points of grammar in English. Whereas direct WCF seems sometimes superior to indirect WCF due to its explicitness, there are still instances where the inductive nature of WCF is not useful for learners. In such cases, learners seem to require some form of ME. However, according to SAT, ME should consist of dec- 
larative knowledge formulated in such a way that it can be converted in a straightforward way into procedural knowledge.

However, formulating declarative knowledge of grammar into a useful format for L2 learners is itself a challenge. For example, as Leroux and Kendall (2018) indicate, even native speakers seem mystified by the nature and purpose of the variation in article use in English. The same can be said for other grammatical contrasts in English and in other languages. In English, for example, learners encounter an elaborate and confusing system of verb tenses, complicated contrasts in preposition selection, and the perplexing contrast in using infinitives or gerunds as verbal complements, among others. This is why the assistance of theoretical linguists would be helpful in an effort to attempt to reduce the many complexities of grammatical patterns such as these into diagnostic tools or mnemonic devices that English language learners might usefully implement to begin to get traction in acquiring such points of grammar. This paper is thus, first and foremost, a call for theoretical linguists, applied linguists, researchers in language pedagogy, and classroom teachers to consider collaborating on the formulation, testing, and implementation of accurate and proceduralizable declarative knowledge (i.e., metalinguistic explanations) relevant to L2 grammar instruction.

Although work in theoretical linguistics would need to be done to understand how to formulate usable diagnostics and similar guidelines for points of grammar in English and other languages, the practical value of formulating such ME is apparent. Learners clearly need accurate and usable ME to make progress with grammatical paradigms beyond the most basic binary paradigms. In fact, there may also be other practical applications for such ME, such as aiding computer scientists working in natural language processing, since today computers can also be considered, in some sense, learners of natural languages.

\section{Acknowledgements}

The author thanks Dr. Jason Wagner and Suet Mui Lam for the assistance they provided.

\section{Conflicts of Interest}

The author declares no conflicts of interest regarding the publication of this paper.

\section{References}

Anderson, J. (1976). Language, Memory, and Thought. Lawrence Earlbaum Associates.

Ashwell, T. (2000). Patterns of Teacher Response to Student Writing in a Multiple-Draft Composition Classroom: Is the Content Feedback Followed by Form Feedback the Best Method? Journal of Second Language Writing, 9, 227-258. https://doi.org/10.1016/S1060-3743(00)00027-8

Bitchener, J. (2008). Evidence in Support of Written Corrective Feedback. Journal of Second Language Writing, 17, 102-118. https://doi.org/10.1016/j.jslw.2007.11.004

Bitchener, J., \& Knoch, U. (2008). The Value of Written Corrective Feeback for Migrant 
and International Students. Language Teaching Research, 12, 409-431. https://doi.org/10.1177\%2F1362168808089924

Bitchener, J., \& Knoch, U. (2009). The Contribution of Written Corrective Feedback to Language Development: A Ten Month Investigation. Applied Linguistics, 31, 193-214. https://doi.org/10.1093/applin/amp016

Bitchener, J., \& Knoch, U. (2010). Raising the Linguistic Accuracy Level of Advanced L2 Writers with Written Corrective Feedback. Journal of Second Language Writing, 19, 207 217. https://doi.org/10.1016/j.jslw.2010.10.002

Bitchener, J., Young, S., \& Cameron, D. (2005). The Effect of Different Types of Corrective Feedback on ESL Student Writing. Journal of Second Language Writing, 14, 191205. https://doi.org/10.1016/j.jslw.2005.08.001

Chandler, J. (2003). The Efficacy of Various Kinds of Error Feedback for Improvement in the Accuracy and Fluency of L2 Student Writing. Journal of Second Language Writing, 12, 267-296. https://doi.org/10.1016/S1060-3743(03)00038-9

Christophersen, P. (1939). The Articles: A Study of Their Theory and Use in English. Einar Munksgaard.

DeKeyser, R. (1998). Beyond Focus on Form: Cognitive Perspectives on Learning and Practicing Second Language Grammar. In C. Doughty, \& J. Williams (Eds.), Focus on Form in Classroom Second Language Acquisition (pp. 42-63). Cambridge University Press.

DeKeyser, R. (2001). Automaticity and Automatization. In P. Robinson (Ed.), Cognition and Second Language Instruction (pp. 125-151). Cambridge University Press. https://doi.org/10.1017/CBO9781139524780.007

DeKeyser, R. (2007). Introduction: Situating the Concept of Practice. In R. M. DeKeyser (Ed.), Practice in Second Language: Perspectives from Applied Linguistics and Cognitive Psychology (pp. 1-18). Cambridge University Press. https://doi.org/10.1017/CBO9780511667275.002

Dryer, M. S. (2013). Indefinite Articles. In M. S. Dryer, \& M. Haspelmath (Eds.), The World Atlas of Language Structures Online. Max Planck Institute for Evolutionary Anthropology. http://wals.info/chapter/38

Ellis, R., Sheen, Y., Murakami, M., \& Takashima, H. (2008). The Effects of Focused and Unfocused Written Corrective Feedback in an English as a Foreign Language Context. System, 36, 353-371. https://doi.org/10.1016/j.system.2008.02.001

Fathman, A., \& Whalley, E. (1990). Teacher Response to Student Writing: Focus on Form versus Content. In B. Kroll (Ed.), Second Language Writing: Research Insights for the Classroom (pp. 178-190). Cambridge University Press. https://doi.org/10.1017/CBO9781139524551.016

Ferris, D. (1999). The Case for Grammar Correction in L2 Writing Classes: A Reponse to Truscott (1996). Journal of Second Language Writing, 8, 1-11. https://doi.org/10.1016/S1060-3743(99)80110-6

Ferris, D. (2004). The “Grammar Correction” Debate in L2 Writing. Where Are We, and Where do We go From Here? (And What Do We Do in the Meantime...)? Journal of Second Language Writing, 13, 49-62. https://doi.org/10.1016/j.jslw.2004.04.005

Ferris, D. (2010). Second Language Writing Research and Written Corrective Feedback in SLA. Studies in Second Language Acquisition, 32, 181-201. https://doi.org/10.1017/S0272263109990490

Ferris, D., \& Roberts, B. (2001). Error Feedback in the L2 Writing Classes: How Explicit Does It Need to Be? Journal of Second Language Writing, 10, 161-184. https://doi.org/10.1016/S1060-3743(01)00039-X 
Fhaeizdhyall, A. (2020). Perceived Effect of Written Corrective Feedback on Collocation Competence of Low-Performing ESL Learners: Factors Contributing to Success, Difficulties and Benefits. Asian Journal of Research in Education and Social Sciences, 2, 149-173.

Gorman, M., \& Ellis, R. (2019). The Relative Effects of Metalinguistic Explanation and Direct Written Corrective Feedback on Children's Grammatical Accuracy in New Writing. Language Teaching for Young Learners, 1, 57-81.

https://doi.org/10.1075/ltyl.00005.gor

Jespersen, O. (1933). Essentials of English Grammar. Henry Holt and Company.

Kepner, C. (1991). An Experiment in the Relationship of Types of Written Feedback to the Development of Second-Language Writing Skills. Modern Language Journal, 75, 305-313. https://doi.org/10.1111/j.1540-4781.1991.tb05359.x

Lalande II, J.F. (1982). Reducing Composition Errors: An Experiment. Modern Language Journal, 66, 140-149. https://doi.org/10.1111/j.1540-4781.1982.tb06973.x

Leroux, W., \& Kendall, T. (2018). English Article Acquisition by Chinese Learners of English: An Analysis of Two Corpora. System, 76, 13-24.

https://doi.org/10.1016/j.system.2018.04.011

Master, P. (1997). The English Article System: Acquisition, Function, and Pedagogy. System, 25, 215-232. https://doi.org/10.1016/S0346-251X(97)00010-9

McLaughlin, B. (1987). Theories of Second Language Acquistion. Edward Arnold.

Nassaji, H. (2011). Correcting Students' Written Grammatical Errors: The Effects of Negotiated versus Nonnegotiated Feedback. Studies in Second Language Learning and Teaching, 1, 315-334. https://doi.org/10.14746/ssllt.2011.1.3.2

Polio, C., Fleck, C., \& Leder, N. (1998). If Only I Had More Time: ESL Learners Changes in Linguistic Accuracy on Essay Revisions. Journal of Second Language Writing, 7, 4368. https://doi.org/10.1016/S1060-3743(98)90005-4

Robb, T., Ross, S., \& Shortreed, I. (1986). Salience of Feedback on Error and Its Effect on EFL Writing Quality. TESOL Quarterly, 20, 83-93. https://doi.org/10.2307/3586390

Russell, J., \& Spada, N. (2006). The Effectiveness of Corrective Feedback for the Acquisition of L2 Grammar: A Meta-Analysis of the Research. In J. M. Norris, \& L. Ortega (Eds.), Synthesizing Research on Language Learning and Teaching (pp. 133-164). John Benjamins Publishing Company. https://doi.org/10.1075/1llt.13.09val

Sheen, Y. (2007). The Effect of Focused Written Corrective Feedback and Language Aptitude on ESL Learners' Acquisition of Articles. TESOL Quarterly, 41, 255-283. https://doi.org/10.1002/j.1545-7249.2007.tb00059.x

Sheen, Y. (2010). Differential Effects of Oral and Written Corrective Feedback in the ESL Classroom. Studies in Second Language Acquisition, 32, 203-234. https://doi.org/10.1017/S0272263109990507

Shintani, N., \& Ellis, R. (2013). The Comparative Effect of Direct Written Corrective Feedback and Metalinguisitic Explanation on Learners' Explicit and Implicit Knowledge of the English Indefinite Article. Journal of Second Language Writing, 22, 286-306. https://doi.org/10.1016/j.jslw.2013.03.011

Shintani, N., Ellis, R., \& Suzuki, W. (2013). Effects of Written Feedback and Revision on Learners' Accuracy in Using Two English Grammatical Structures. Language Learning, 64, 103-132. https://doi.org/10.1111/lang.12029

Sinclair, J. (Ed.) (1991). Corpus, Concordance, Collocation. Oxford University Press.

Stefanou, C., \& Révész, A. (2015). Direct Written Corrective Feedback, Learner Differences, and the Acquisition of Second Language Article Use for Generic and Specific Plural Ref- 
erence. The Modern Language Journal, 99, 263-282.

https://doi.org/10.1111/modl.12212

Sweet, H. (1900). A New English Grammar: Logical and Historical I. Clarendon Press.

Truscott, J. (1996). The Case against Grammar Correction in L2 Writing Classes. Language Learning, 46, 327-369. https://doi.org/10.1111/j.1467-1770.1996.tb01238.x

Truscott, J. (1999). The Case for "the Case for Grammar Correction in L2 Writing Classes": A Response to Ferris. Journal of Second Language Writing, 8, 111-122. https://doi.org/10.1016/S1060-3743(99)80124-6

Truscott, J. (2004). Evidence and Conjecture: A Response to Chandler. Journal of Second Language Writing, 13, 337-343. https://doi.org/10.1016/j.jslw.2004.05.002

Truscott, J. (2007). The Effect of Error Correction on Learners' Ability to Write Accurately. Journal of Second Language Writing, 16, 255-272. https://doi.org/10.1016/j.jslw.2007.06.003

Truscott, J., \& Hsu, A. (2008). Error Correction, Revision, and Learning. Journal of Second Language Writing, 17, 292-305. https://doi.org/10.1016/j.jslw.2008.05.003

Wagner, J. \& Wulf, D. (2016). Understanding Written Corrective Feedback in SecondLanguage Grammar Acquisition. Journal of Education and Learning, 5, 259-277. https://doi.org/10.5539/jel.v5n4p259

Wagner, J. (2016). An Explanation of the Effectiveness of Written Corrective Feedback in Second-Language Grammar Acquisition. Ph.D. Dissertation, George Mason University.

Wulf, D. (2016). Assistance in Learning and Teaching the English Article System: Diagnostics and Mnemonics. Open Journal of Modern Lingustics, 6, 317-328.

https://doi.org/10.4236/ojml.2016.64032 